\title{
APORTE A LA FORMACIÓN MILITAR DESDE LOS EFECTOS POR CONDENAS A MILITARES: TRES ESTUDIOS DE CASO
}

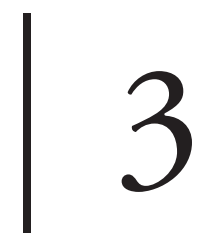

\author{
Liliana Andrea Murillo Pardo ${ }^{1}$ \\ Estefany Pita Tunjar ${ }^{2}$
}

\section{Resumen}

Las condenas militares a Oficiales del Ejército Colombiano han tenido diferentes matices, dada la complejidad de algunos casos; por lo que este tema se convierte en un elemento de reflexión interno para reconocer la experiencia y los efectos de estos procesos. En este sentido se retoman algunos casos de condenas militares describiendo sus principales efectos. El presente capítulo en ningún momento pretende realizar un análisis jurídico de los casos, sino presentar de manera descriptiva los principales efectos sobre todo a nivel social y el lugar de las Ciencias Militares en este estudio. Este capítulo está asociado a un trabajo de grado de la Facultad de Ciencias Militares.

Palabras clave: Condenas militares, Efectos, sociales Ciencias Militares.

\begin{abstract}
The military condemnations of Colombian Army officers have had different nuances, given the complexity of some cases; so this topic becomes an element of internal reflection to recognize the experience and the effects of these processes. In this sense, some cases of military convictions are recounted, describing their main effects. The present chapter at no time intends to carry out a legal analysis of the cases, but to present in a descriptive manner the main effects, especially at the social level and the place of the Military Sciences in this study. This chapter is associated to a degree work of the Faculty of Military Sciences.
\end{abstract}

Key words: Military sentences, Effects, social Military Sciences.

1 Ingeniera de Sistemas, Especialista en Investigación y docencia Universitaria, Magíster en Educación. Contacto: andre.murillo201@gmail.com

2 Oficial del Ejército Peruano, en comisión de estudios en Colombia. Contacto: ptestefany@hotmail.com 


\section{Introducción}

Uno de los valores más importantes en los militares, es la lealtad, el cual va seguido del valor y el sacrificio, entre otros; la formación militar ha demostrado que el cumplimiento del deber es primordial en su carrera profesional, lo cual es infundado desde el Alma Máter de los Oficiales, Escuela Militar de Cadetes "General José María Córdova" en espacios de formación académica y militar.

En este proceso la historia militar se convierte en un fundamento importante para permanentes análisis y reflexiones sobre lo que implica el cumplimiento del deber para un Oficial. Muchas veces, en su afán por cumplir con una misión encomendada, se han cometido errores de grandes magnitudes, por lo cual muchos están pagando grandes condenas, causando sufrimientos en ellos mismos y en sus familiares, sin esperanzas de una pronta recuperación de la libertad, pues aunque estaban en cumplimiento de un deber, de una orden, en defensa de una Nación; un paso en falso ha sido el que ha marcado sus destinos y ha terminado con sus carreras.

Del mismo modo, es el sistema de formación Militar en la mayoría de los países latinos, tales como Perú y Argentina. Argentina, por ejemplo, ha sido un país con alto número de condenas a Militares y donde más sienten los familiares de los detenidos la fragilidad del sistema es en la atención de la salud y el buen trato. "Hay 300 presos políticos con más de 80 años y 460 tienen entre 70 y 79", "Como muchos todavía afrontan juicios, cada vez que tienen que presentarse en el juzgado los despiertan a las cuatro de la mañana, los llevan esposados en camiones que pasan por distintos penales. Muchos no tienen estabilidad y hay quienes se hacen encima. Llegan al tribunal en condiciones deplorables", relató el Señor Cr. Retirado. Guillermo Viola.

Asimismo, en Perú, existe un sin número de militares en las cárceles, en su mayoría condenados por estar en el cumplimiento de su deber, algunos tal vez por errores que causaron daños a la población civil, otros porque no midieron las consecuencias de sus actos en el momento de llevar a cabo las misiones que se les fue encomendada, algunos de ellos relatan que todo fue por un afán de dar un resultado positivo para sus comandantes.

De cualquier modo, están pasando por circunstancias difíciles, junto con sus familiares y el gobierno parece haber olvidado bajo qué condiciones sucedieron los hechos. Es así como se pretende hacer un relato de lo que ha sido el resultado de algunos errores en el cumplimiento del deber de algunos Oficiales de Colombia, Argentina y Perú.

Existen diferentes casos en los que los militares de estos tres ejércitos se han visto involucrados en condenas en cumplimiento de su deber. El estudio desarrollado retoma tres casos, cada uno en uno de esos países. 
El 17 de diciembre de 1996, un grupo de 14 miembros del MRTA incursionaron en la residencia del Embajador del Japón en el Perú, Morihisa Aoki, mientras se desarrollaba una recepción con motivo del aniversario del natalicio del emperador Akihito. Los "emerretistas" ingresaron a la residencia fuertemente armados a través de un forado de una casa vecina, logrando tomar como rehenes a más de 700 invitados.

Sus exigencias eran: la liberación de los miembros del MRTA que estaban encarcelados en distintas prisiones del país, el traslado de los liberados y los captores a la selva central, el cambio de política económica y el pago de un impuesto de guerra.

Quien dirigió la operación fue Néstor Cerpa Cartolini, cabecilla emerretista que por aquel entonces era prófugo de la justicia peruana. Paralelamente, se desarrolló un plan militar para rescatar a los rehenes. Para ello, el Comando Conjunto de las Fuerzas Armadas encargó al jefe de la División de Fuerzas Especiales del Ejército, general Augusto Jaime Patiño, la elaboración de dicho plan operativo. El general EP José Williams Zapata, por encargo de Jaime Patiño, diseñó el plan de operaciones "Nipón 96” y, posteriormente, se encargó de dirigir al grupo de 143 comandos, conocido como "Patrulla Tenaz", que finalmente tomaría la residencia. De acuerdo a lo referido por Williams, en la operación se empleó la táctica conocida como "tiro instintivo selectivo", consistente en efectuar tres disparos en dos segundos a las partes vitales del adversario y posteriormente hacer un tiro a la cabeza para asegurarse que éste quede fuera de combate. A raíz de esta operación, se han puesto en duda los procedimientos ejecutados por los comandos que participaron en esta.

En el caso de Argentina se ha presentado un padecimiento de condenados debido a la represión subversiva que atravesaba el país, provocando así la creación de movimientos liderados por los familiares de los militares juzgados.

En el contexto armado colombiano, los miembros de las Fuerzas Armadas se han visto afectados por errores en procedimientos que algunos militares han cometido dentro del conflicto, dando paso a ejecuciones extrajudiciales y manipulaciones para inculparlos.

Tal es el caso del Coronel Plazas Vega, quien dirigió la operación de defensa en contra del M-19 en la toma del Palacio de Justicia, en donde hubo desapariciones y muertes de muchas personas, algunas de ellas sin aclarar, es así como se inicia una investigación en contra de quienes hicieron parte de este proceso y posteriormente la condena.

Por ello, se ha sacado un resultado de una investigación realizada en los países Colombia, Argentina y Perú, aquí se evidencian las consecuencias económicas, psicológicas, sociales, familiares, entre otras, que genera una condena para un militar juzgado por sus acciones en operaciones militares a lo largo de la historia en países de América. Se pudo determinar el nivel de afectación de los militares y la perdida de bienestar. 
De este modo, se comprendió cómo surgen las condenas de los militares involucrados en procesos judiciales, apoyándonos en la ejecución de entrevistas a los condenados en Colombia, Argentina y Perú con miras a realizar un análisis comparativo lo cual permitió la complementación y ampliación de la visión de los altos mandos militares y de quienes estarán a cargo de elaborar el marco de una futura justicia transicional colombiana.

A lo largo de la historia de los conflictos armados en países de América Latina, muchos de los militares se han visto involucrados en procesos legales, debido a las operaciones efectuadas. De este modo, se quiere evidenciar cómo las condiciones de los marcos jurídicos en Colombia, Argentina y Perú afectan a los militares condenados y a sus familias.

En la actualidad en Argentina existen militares condenados a pena de muerte por delitos cometidos en la dictadura; en Colombia y en Perú hay militares recluidos por acciones realizadas en operativos en medio del conflicto armado. Dichos militares han dedicado varios años de vida al servicio del Estado cumpliendo misiones emanadas de decisiones políticas. De acuerdo a lo anterior, es pertinente mostrar las consecuencias económicas, psicológicas, sociales, familiares, entre otras, que genera la reclusión para un militar y para su entorno familiar.

Por ello, surge nuestra pregunta de investigación; ¿Qué consecuencias produce en su entorno personal y familiar, la reclusión de un militar tras una investigación por actos del servicio en desarrollo de operaciones de orden público en Colombia, Argentina y Perú?

De este modo se han fijado unos objetivos que nos permitan hallar unas conclusiones y nos puedan responder nuestra pregunta de investigación; considerando que nuestro principal objetivo viene siendo, elaborar un análisis comparativo de los militares condenados por acciones dentro de los distintos conflictos armados en los países a estudiar.

Entonces, si queremos ser consecuentes con este objetivo, se han fijado los objetivos específicos que nos ayudarán a alcanzar el general, siendo así:

- Identificar las características económicas, sociales, familiares, psicológicas y laborales de la situación actual de los militares condenados.

- Determinar los procedimientos jurídicos que se llevan a cabo con los militares en estos países.

- Analizar las distintas realidades y situaciones en que se presentan las condenas a los militares en Colombia, Argentina y Perú. 


\section{Método de investigación}

Investigación descriptiva que busca explicar los aspectos más característicos, distintivos y particulares de la justicia penal militar de cada país a tratar, identificar la pérdida de bienestar consecuencia de las condenas emitidas, el grado de afectación sufrida, efecto psicológico, tiempo y condiciones de las sentencias.

El proceso metodológico Cualitativo son los contenidos científicos específicos de la comunicación, lo que facilita obtener una panorámica real de lo que está ocurriendo en los países que son objeto de investigación, en segundo lugar la recolección de la información permite un análisis de fondo que evidencia una problemática moral en las familias de los militares que se encuentran vinculados a las condenas por actos del servicio, entonces podemos ver las bondades cualitativamente del entorno de investigativo como también del desarrollo del proceso.

Es así como facilita el diseño de la investigación, al analizar la información teórica, con la obtenida por medio de las entrevistas hechas a algunas de las personas que hacen parte de la investigación, pues de este modo permite una mayor facilidad de interpretación y análisis de datos por complementariedad de la información la cual se corrobora mutuamente, obteniendo conclusiones veraces.

Las técnicas de recopilación y análisis usadas fueron:

a. Socialización de la temática por parte del investigador, hacia los actores sociales de estudio, y la organización, para armar una idea global general de lo que fueron los casos de los 3 países motivo de la presente investigación.

b. Argumentación de los procedimientos, necesarios que indiquen que la investigación y estructuración de la información, estén enfocados en la temática trabajada, fundamentada en el que, como, y para qué.

c. Entrevistas estructuradas aplicadas a militares Colombianos y Peruanos condenados y a sus familias.

d. Revisión bibliográfica de fuentes que evidencian el contexto de los conflictos a lo largo de la historia en Colombia, Argentina y Perú. Revisión bibliográfica de la situación de los militares condenados y detenidos en las cárceles en los países a estudiar.

\section{Fundamentos legales}

En Argentina, por acción u omisión de las autoridades públicas, se cometieron en el país en el periodo de 1975 a 1979 numerosas y graves violaciones de derechos 
humanos, donde se habla de la desaparición de alrededor de 4.162 personas. Con respecto al juzgamiento de los militares vinculados al gran número de desaparecidos a lo largo de sus dictaduras, según el art. 11 de la ley 23.049 del 9/2/84, se evidencia que quienes "cumplieron órdenes" propias del plan criminal no podrán beneficiarse con la eximente de "obediencia debida" (Asociación Americana de Juristas, 1997). También se creó la Comisión Nacional sobre la Desaparición de Personas teniendo como objetivo intervenir activamente en el esclarecimiento de los hechos relacionados con la desaparición de personas, teniendo la facultad de requerir a cualquier funcionario del Poder Ejecutivo Nacional y de las Fuerzas Armadas con cumplimiento estricto (EQUIPO NIZKOR, s.f.). Gracias a la sanción de la ley que deroga el código de Justicia Militar los efectivos de las Fuerzas Armadas pasaron a ser juzgados por la justicia federal, en acuerdo con los códigos Penal y Procesal Penal (Ybarra, 2008).

La justicia militar en Perú considerando los diferentes casos de militares juzgados, no se mantiene aislada de la justicia ordinaria, sin embargo, más allá de adoptar una postura doctrinaria acerca de la viabilidad de la justicia militar en el Estado peruano. "En los últimos años debido a los problemas subversivos que afrontó el país en los años 80 la constitución de 1993 con la Ley 29.182 define la justicia militar de manera independiente al poder judicial" (congreso.gob).

El Consejo Supremo de Justicia Militar, es el organismo máximo que emite las sentencias tanto a las Fuerzas Militares y Policía Nacional, las limitaciones en cuanto a los miembros que conforman este consejo militar está dada por "la ley 163 de organización, funciones y competencia de la jurisdicción especializada en materia Penal Militar Policial en la cual se establece que "Únicamente quienes poseen formación jurídico militar policial, pueden desempeñarse como Fiscales Penales Militares Policiales, o Fiscales Adjuntos Penales Militares Policiales, en cualquiera de sus niveles funcionales" (Art. 51, 51.2, Pg. 37)

Conforme a la Constitución Política peruana, la Justicia Militar tiene un rol preponderante en la protección de los derechos humanos, principalmente por dos factores; porque la jurisdicción especializada es el instrumento que garantiza la efectiva defensa y seguridad de la República, toda vez que asegura que los efectivos militares y policiales cumplan con la idoneidad sus funciones constitucionales; otro factor importante es que la justicia militar vela que los efectivos del orden ejerciten sus funciones con estricto respeto de los derechos de los ciudadanos; es decir, previene toda distorsión o exceso funcional que atente o lesione los derechos de la persona humana (C.P.P, 1993).

En Colombia existe una Justicia Penal Militar que juzga a los sujetos activos que hayan tenido una conducta ilícita. Según lo establece el artículo 221 de la Constitución Política: 
"Los delitos cometidos por los miembros de la fuerza pública en servicio activo y en relación con dicho servicio, son de competencia de las cortes marciales o tribunales militares. Dichas cortes o tribunales estarán integradas por miembros de la fuerza pública en servicio activo o en retiro" (Renteria, s.f.).

A su vez, según el artículo 221 de la Constitución en la investigación y juzgamiento de las conductas punibles de los miembros de la Fuerza Pública, en relación con un conflicto armado o un enfrentamiento que reúna las condiciones objetivas del Derecho Internacional Humanitario, se aplicarán las normas y principios de este. Los jueces y fiscales de la justicia ordinaria y de la Justicia Penal Militar o Policial que conozcan de las conductas de los miembros de la Fuerza Pública deberán tener formación y conocimiento adecuado del Derecho Internacional Humanitario.

Pues todas aquellas conductas que sean abiertamente contrarias a la función constitucional de la Fuerza Pública y que por su sola comisión rompan el nexo funcional del agente con el servicio, han de entenderse excluidas del campo de competencia de esta jurisdicción especial.

\section{Resultados y análisis}

Así, se ha podido evidenciar que, a lo largo de la historia, los conflictos armados que han atravesado estos países aquí nombrados, han dejado consecuencias en muchos de los Oficiales que han estado al frente de importantes situaciones de guerra y estas consecuencias no han sido reflejadas no solo en su ámbito laboral sino también en el personal y familiar, por lo cual a continuación se enunciarán estas consecuencias de acuerdo a las categorías (Familiares, profesionales y personales) por país.

\section{Consecuencias familiares}

Las consecuencias familiares se refieren a todo aquello que pone en riesgo la estabilidad física y emocional de las personas que acompañan de cerca a cada uno de los militares.

\section{Argentina}

Como seres humanos, somos integrales, todo aquello que afecta nuestra humanidad, involucra a todos los que nos rodean por ello, es importante referirnos puntualmente a estas consecuencias. 
Con respecto al caso Gustavo Boccalari, quien fue oficial subinspector segundo en la Brigada de Investigaciones de Bahía Blanca, Su esposa Nélida Ester Weimann, quedó cuadripléjica en el año 1967 y en el 2007 se le diagnosticó vejiga e intestinos neurogénicos por colapso renal debido a deterioro de la función vesical por lo que la vesícula debe ser vaciada mediante cateterismo intermitente cada 4 horas. Todos los cuidados los realizaba su marido Boccalari. La Cámara Federal de Bahía Blanca le revocó la prisión domiciliaria el 24 de abril de 2013 porque no se cumplían los extremos que marca la ley, por lo que fue enviado a la prisión de Marcos Paz.

Además de la degradación del estado de su esposa, el 24 de junio de 2013 Boccalari tuvo un episodio de hipertensión con pérdida de conocimiento del cual no ha tenido un diagnóstico (Asociación de Abogados por la Justicia y la Concordia, 2015).

\section{Colombia}

En cuanto al Coronel Plazas Vega, ha manifestado que Su familia está constituida por su esposa y sus cinco hijos; nueve nietos profesionales. Reconoce que han estado viviendo dispersos, pues "no puede uno estar participando en eventos que normalmente son de asistencia obligatoria, en razón afectiva, y temas como bautizos, enfermedades, cumpleaños". Explica que temporalmente alguno de los hijos puede visitarlo y que tres de ellos no viven acá en Colombia; "los tres hombres mayores viven fuera del país por razones de trabajo... y también de seguridad, posteriormente pues tuvimos amenazas, uno de mis hijos iba a ser secuestrado por una célula del M-19, y hubo dos intentos que afortunadamente se lograron desarticular: contra mi residencia y otro dentro de la Universidad Militar" que se pudieron neutralizar.

\section{Perú}

Hoy en día el General Roble Espinoza junto con sus familias viven en Guatemala junto a sus hijos y esposa "Las penas previstas para estos delitos contemplan la imposición de una pena de prisión de 15 años. Además, el Fiscal solicitó que se condenara al General Robles al pago de US\$ 4.500 .000 en concepto de "reparación civil". Por tal motivo, se ordenó el embargo preventivo de los bienes patrimoniales, ahorros y pensión de retiro del general Rodolfo Robles Espinoza." (CIDH, 1999)

La familia del militar sentenciado se vio afectados ya que fueron despojados de su vivienda, motivo por el cual reclamaron sus bienes por que todas las cosas decomisadas 
eran propiedad de la esposa y no del militar, cabe resaltar que tras este hecho la familia de este militar se desmoronó y los daños son irremediables.

\section{Consecuencias profesionales y personales}

\section{Argentina}

La reclusión de los represores de las dictaduras, en la mayoría de centros penitenciarios se ha destinado pabellones exclusivamente para los condenados por delitos de lesa humanidad. Aunque desde el año 2014, se ha venido presentando un "incremento de la tasa de encarcelamiento y la insuficiencia de plazas disponibles para alojar a los militares" (Vedia, 2014) pues se habla que desde el 2009 el número de internos ha crecido en un 150\% (Vedia, 2014), como es el caso de la cárcel Marcos Paz donde la mayoría de presos son gente de tercera edad y muchos de ellos requieren tratamientos médicos especiales, pues según Jorge Goncalvez, jefe del servicio médico, se encuentran "internos con afecciones cardiopatías, neurológicas, con mal de Alzheimer, que requieren una atención constante... muchos presentan cuadros de psicopatía, es decir que son conscientes de lo que hicieron pero tienen alterada su escala de valores: cree que lo que hizo fue lo mejor" (Aguilas Humanas, 2010).

En el año 2010 el sacerdote Christian Von Wernich y el ex militar Miguel Etchecolatz mantuvieron una huelga de hambre en protesta a las condiciones de detención reclamando "una mejor atención y en rechazo al abandono médico al que son sometidos" (EL MUNDO.es, 2010).

Así mismo, recientemente ha aumentado el número de traslados de presos del centro penitenciario Marcos Paz a la cárcel Ezeiza, sobre todo por motivos de salud, muchos ya ancianos de 85 años, en silla de ruedas. Según Cecilia Pando, activista argentina, esposa del mayor retirado Pedro Rafael Mercado, y de la asociación de apoyo a los represores, de aproximadamente 360 presos por delitos de lesa humanidad que se encuentran actualmente, alrededor de 200 tienen más de 70 años (Clarín, 2014).

Los traslados se han llevado a cabo sin previo aviso a los militares como las mujeres que se encontraban alojadas en Ezeiza, por lo que la reubicación aconteció "en medio de tensiones y preocupación por parte de los familiares, que deploraron la "improvisación" del operativo. Algunos fueron subidos a los micros y después retornados a su celda, quedando a la deriva el bolso que habían armado con los remedios" (Vedia, 2014).

En la actualidad el número de procesados asciende a los 1100, dentro de los cuales hay "970 imputados detenidos, ya sea en unidades penitenciarias (57\%), sus domicilios (40\%), dependencias de la fuerzas de seguridad $(1,5 \%)$ y en hospitales $(0,5 \%)$, mien- 
tras que los condenados alcanzan el número de 563” (Santi \& Riera, 2015). Es decir que existen muchos procesados sin condena durante largos años, donde el promedio de edad de los involucrados es de 73 años y el tiempo de prisión preventiva supera los 6 años (Gabetta, 2016). Además, han muerto 314 presos por falta de una adecuada atención médica, que equivale a un 15\% del total de presos (Asociación de Abogados por la Justicia y la Concordia, 2015). Entre los fallecidos en cautiverio se encuentra el caso de Félix Alejandro Alais que estaba preso en el Complejo Penitenciario Federal II de Marcos Paz y se hallaba grave a causa de su diabetes insulinodependiente y sus serios problemas respiratorios (enfisema pulmonar). A pesar de las denuncias por el abandono y las siete veces que el médico del Módulo IV Dr. Legrand solicitó a sus superiores una atención adecuada, esta jamás ocurrió y subsistía con la medicación y atención que le brindaban otros internos. Falleció el 6 de agosto de 2012 internado en el hospital de Marcos Paz (Asociación de Abogados por la Justicia y la Concordia, 2015). Otro caso es el del Coronel Retirado Carlos Alberto Roque Tepedino quien fue trasladado al Complejo Penitenciario Federal II de Marcos Paz en el 2010, se le habían extraído tres pólipos malignos de la vejiga y se encontraba en un serio estado depresivo. No recibió el tratamiento psiquiátrico ni tampoco la atención médica necesaria por lo que falleció a sus 84 años el 12 de noviembre de 2011 (Asociación de Abogados por la Justicia y la Concordia, 2015).

Con respecto a los enfermos graves se encuentra el caso de Luis Abelardo Patti de 60 años, quien fue oficial subinspector de la comisaría de Escobar. A raíz de un accidente cerebrovascular (ACV) sufrido en el 2010 perdió su movilidad porque no controla su equilibrio, este provocó la ceguera de su campo visual izquierdo e incontinencia esfinteriana. Encontrándose en el Instituto FLENI para un plan de rehabilitación los jueces Lucila E. Larrandart y Héctor O. Sagretti ordenaron su inmediato traslado a la cárcel de Devoto.

Mediante un habeas corpus fue evacuado para finalmente ser trasladado en agosto del 2011 al penal de Ezeiza donde se encuentra actualmente. Haciendo caso omiso de la opinión médica, ha sido obligado a concurrir a numerosas audiencias soportando dolores cervicales, hipertensión y náuseas. Se encuentra en silla de ruedas, no está en condiciones de auto valerse para movilizarse, para satisfacer elementales necesidades fisiológicas o higienizarse, acciones que exigen la ayuda de otros internos pues corre serio riesgo de quedar parapléjico. Por los delitos de violación de funcionario público, abuso de autoridad, prevaricato del juez de hecho y de derecho, vejación contra la persona del detenido, imposición a éste de tortura y homicidio en grado de tentativa, Patti formuló una denuncia el día 25 de julio de 2011, ante el Juzgado Federal en lo Criminal y Correccional No. 2 de San Isidro (Asociación de Abogados por la Justicia y 
la Concordia, 2015). En otro caso, Gustavo Boccalari de 64 años, quien fue oficial subinspector segundo en la Brigada de Investigaciones de Bahía Blanca y en la Subcomisaria de Darregueira (Centro de Información Judicial, 2012), padece de leucemia crónica a linfocitos granulares grandes, hipertensión y tuvo un infarto agudo de miocardio.

\section{Colombia}

A raíz de la toma del Palacio de Justicia llevada a cabo por el M-19 el 6 de noviembre del año 1985, persisten las secuelas en el país y aun con muchos interrogantes de lo que sucedió durante esas 28 horas.

Paradójicamente ningún hecho como la toma armada y sangrienta del Palacio por parte del M-19 y la operación de respuesta del Estado Colombiano, sigue generando profundas divisiones en el país, entre verdades y dudas que no permiten una aclaración de los hechos sucedidos, por ello, han sido juzgados varios militares vinculados al operativo de la retoma del palacio por aquellos desaparecidos que dejó este.

Uno de los casos es el del coronel Luis Alfonso Plazas Vega quien fue condenado penalmente con base en los siguientes puntos: "tuvo mando en la retoma del Palacio de Justicia, tuvo responsabilidad en el manejo de los rehenes liberados y controló lo que sucedía en la Casa del Florero, a donde éstos fueron conducidos. La mayoría salieron vivos de ahí, pero otros desaparecieron" (La silla vacía, 2011).

Este caso ha presentado varias irregularidades e incluso denuncias penales por parte del coronel retirado a la fiscal Ángela María Buitrago por haber usado un testigo falso.

En el transcurso de una entrevista realizada al General Arias Cabrales, el día 8 de julio del 2016 hacia las 15 horas, quien se encuentra recluido en la Escuela de infantería hace ocho años por los hechos ocurridos en la retoma del Palacio de Justicia donde, se empezó hablando de cómo estaba constituido su núcleo familiar en estos momentos de la condena en la que se encuentra. Expresó que "desafortunadamente en estos casos de la justicia, se afecta no solamente una persona, a quien se vincula a un proceso, sino también de paso la familia" (Pita, 2017).

Al preguntar sobre cómo se había llevado a cabo el proceso de notificación de la condena, el general narra que "la fiscal que llevaba el caso, al resolver mi situación jurídica, decidió privarme de la libertad a pesar de que yo, desde el mismo año de 1985, había estado asistiendo a todas las diligencias a las cuales me habían citado y de igual manera la fiscalía, cuantas veces se me requirió yo hice presencia allá. Sin embargo, entonces la señora fiscal emite el concepto de que por tratarse de una persona de peligro para la sociedad tenía que privarme de la libertad entonces sin haber sido llamado a juicio todavía" (Pita, 2017). 
Posteriormente por autorización de la directora del INPEC se le permitió permanecer en la Escuela de Infantería, aunque cuando las personas mayores de 65 años tienen derecho al beneficio de prisión domiciliaria, este no es el caso, pues debería estar en su domicilio natural, y se encuentra dentro de la unidad militar, también añadió "he tenido bastantes altibajos en mi salud. A partir de la detención llevo ya siete intervenciones quirúrgicas, durante este tiempo que estado hospitalizado en varias oportunidades, no solamente por la parte quirúrgica sido por otras afecciones" (Pita, 2017). Aunque afirma que se mantiene esperando que haya decisiones por parte de la Corte Suprema de Justicia para que le resuelvan la situación como ha venido sucediendo en el caso del Coronel Plazas y en el caso del General Ramírez.

Cuando se le preguntó si había tenido algún inconveniente en el ámbito económico a raíz de esa situación, contestó: "traslado este problema a otros miembros de la institución de rangos inferiores que no tienen recursos económicos disponibles, en mi caso pues he tenido que recibir apoyo. Desde el año 2005 he tenido que sufragar los gastos de la defensa, asesorarme de profesionales del derecho con las correspondientes capacidades y eso pues implica gastos”. (Pita, 2017). Además, narra que cuando se produce la pérdida de libertad se encontraba laborando en la Escuela Militar como director de estudios superiores universitarios y tenía sus entradas económicas adicionales, que a partir de ese momento se perdieron.

Entonces acepta que "hay restricciones, limitaciones, pero las pienso con mayor dimensión con aquellas personas, soldados, suboficiales que tienen sus familias abandonadas, sin tener otros recursos" (Pita, 2017).

Se preguntó por si hay algún tipo de reglamentación con respecto a las visitas de sus familiares, a lo que respondió que, si hay algunas normas, por lo que tiene escrita una lista de sus familiares inmediatos; sus hijas, sus nietos, que están residiendo acá en Bogotá.

Y el resto que lo visita esporádicamente, en la guardia tiene el acceso, con identificación y asignándose alguien que los acompañe. Añade que "esos son limitantes que habitan todo el día y ahora mi situación, mi movilidad se delimita acá en la Escuela de Infantería, desde el comando hasta la catedral, que es lo que tengo yo para caminar, hacer algo de movilidad en el día" (Pita, 2017). En el caso de las citas médicas, según el general: "en este momento ya se vuelven casi que consuetudinarias, con razón pues de la edad y de las afecciones. También uno somatiza todas estas circunstancias y le van causando perjuicios a la salud" (Pita, 2017). Para asistir a las citas médicas, tiene que pasar con anterioridad de una semana, la solicitud escrita, la copia de la orden médica, debe salir con acompañamiento.

A lo que añadió: "Inclusive hasta el médico firma que si asistiré a la cita y qué estaría tales horas y demás... Son una serie de restricciones desconocidas para uno en 
mucho tiempo" (Pita, 2017). También cuenta que existen unos protocolos muy establecidos para poder asistir a las citas médicas y con frecuencia están yendo para pasar inspección por parte de La Picota, ya que, aunque el área está habilitada como Centro de Reclusión Militar en la Escuela de Infantería de todas maneras tienen la súper vigilancia por parte de La Picota.

Asegura que el trato que reciben sus familiares al visitarlo es un tratamiento digno, correcto, aunque "no deja de ser un tanto humillante que después de haber ejercido el Comando del Ejército, este uno en circunstancias como estas. Afirma: Para moverme antes, mi acompañamiento era mi escolta natural, de seguridad, porque como corresponde aquí, estaba ejerciendo un cargo. Ahora es puesta en otra forma, no como seguridad, si no para que no se vaya a evadir, entonces ese cambio es un tanto traumático" (Pita, 2017).

$\mathrm{Al}$ indagar por la convivencia con sus familiares, responde que "cambia la vida después de recibir la condena, para fortuna mía los cambios se traducen únicamente en la dificultad de la distancia, en la imposibilidad de acompañar a la nieta en su grado de secundaria o el nieto al momento del bautizo o alguna de esas ceremonias, actividades que sean tan propias de la familia afectiva, pero de resto tengo la fortuna de que todos los días están a través de mi esposa o a través mío llamando, preguntando, y cuando tienen la oportunidad de venir...hace un poco menos pesada la cruz que nos toca cargar en este momento" (Pita, 2017).

En el caso de sus familiares, sus hijos y demás, se preguntó cómo se vio afectada su capacidad de sociabilizar. A lo que contestó que "afortunadamente ellos, desde que terminó la operación de la Toma del Palacio de Justicia, siempre han estado de una manera muy solidaria para mí en ese momento...desde ese momento he tenido siempre el respaldo, ellos son conocedores de mi inocencia, a mí en ninguno de los procesos, en ningún momento nadie ha podido decir usted es responsable de haber emitido esta orden, mi sanción es por omisión, simplemente porque estaba en el cargo; ejercía el cargo de comandante de la brigada. Entonces todos son totalmente conscientes de esa circunstancia y ellos se consideran víctimas también de las injusticias que están cometiendo, pero en ningún momento dicen tenemos que avergonzarnos y ellos a través de la comunicación familiar han hecho incidencia en que mis nietos no se sientan avergonzados, porque su abuelo está acá, sino todo lo contrario y que afortunadamente tenemos unas convicciones religiosas muy sólidas, muy firmes de que la justicia tarde o temprano va a pronunciarse" (Pita, 2017).

Posteriormente se le pregunta si en algún momento había visto vulnerados sus derechos o los de su familia por ser partícipe de este caso, a lo que respondió "solamente lo he sentido por parte de alguno de los operadores de justicia que se manifestaron 
muy sesgada. De esos fallos... pero de resto yo tengo la fortuna de que a mi salida casi obligada al Hospital Militar con la gente que me encuentro, que fueron mis subalternos hace 30, 40 años, se me acercan siempre con todo el respeto, con toda la solidaridad y con sentimientos de amistad a decirme estamos acompañándolo. Muchas personas me dicen en las oraciones también lo estamos acompañando de manera que eso es un paliativo para todas las circunstancias que está uno viviendo, es un analgésico para el corazón” (Pita, 2017).

También opina que en el caso de Colombia “tenemos la guerra jurídica y la guerra mediática, que van paralelas, entonces en este momento muchos de los casos de militares, somos prisioneros políticos que están inculpando. Es parte de la guerra política, porque manipulan los medios de comunicación, tienen periodistas a quienes les pagan y dan recompensa, porque les hagan el favor de publicar noticias sesgadas o en determinado momento y que tienen también conexiones de que va a haber algún fallo, y de antemano antes de que el implicado lo conozca o lo notifiquen formalmente, ya algún medio de comunicación, ha filtrado la noticia.

Según un artículo publicado en el diario El Colombiano, Rafael Nieto Loaiza asegura que la sentencia de Plazas Vega "no respeta los principios fundamentales del derecho penal. La pérdida de la libertad debe ser siempre una medida excepcional y a nadie se le debe condenar sino con prueba inequívoca de su responsabilidad en el delito" (Loaiza, 2012). Además, asegura que como no hay prueba contundente de que Plazas haya desaparecido u ordenado desaparecer a nadie, lo han condenado como "autor mediato en un aparato organizado de poder" (Loaiza, 2012).

Otro caso importante es del ex comandante del B-2 del Ejército, teniente coronel Edilberto Sánchez Rubiano fue condenado a 40 años de prisión por la desaparición de 11 personas en el año 1985 durante la toma de M-19 (EL ESPECTADOR, 2016). El comandante Sánchez estaba encargado de recibir, interrogar y clasificar a los sospechosos que fueron rescatados del palacio de justicia. También la Fiscalía pidió al juzgado condenar a los exmilitares Óscar William Vásquez, Antonio Rubay Jiménez, Luis Fernando Nieto y Ferney Martin Causalla Peńa por el delito de desaparición (EL TIEMPO, 2016). Cabe aclarar que se presume que estas sentencias son producto de presiones políticas.

\section{Perú}

En Perú de acuerdo a los diferentes casos de muertes, matanzas que se presentaban en esa etapa crítica de la historia peruana, como es el caso de la muerte de nueve estudiantes y un profesor en la universidad Enrique Guzmán y Valle (la cantuta) y Barrios Altos. 
El 6 de mayo de 1993 el general Rodolfo Robles Espinoza en defensa y el honor del Ejército Peruano, en su calidad de comandante de la Escuela de Instrucción del Ejercito (COINDE), y ex-jefe de la tercera región de Arequipa; era técnicamente el tercer hombre de poder en la jerarquía militar del Ejército peruano.

Fue condenado y victimizado, debido a información recibida por parte de sus compañeros de arma de su más absoluta confianza, sobre la existencia de la actuación del grupo Colina conocido como el "Escuadrón de la Muerte" organizado por el servicio de inteligencia (SIN) de Perú; fue lo que provocó que mi general Robles, realizara una denuncia pública tras los hechos criminales que venían sucediendo.

El 5 de mayo de 1993, el general Rodolfo Robles denunció públicamente que el Servicio de Inteligencia Nacional del Perú, había organizado un "Escuadrón de la Muerte", denominado Grupo Colina, encargado de la eliminación física de terroristas. De acuerdo a su denuncia, los miembros de este grupo armado habían sido los responsables de la detención ilegal y posterior ejecución extrajudicial de un profesor y nueve estudiantes de la Universidad de La Cantuta, hecho ocurrido el 17 de julio de 1992, así como de la matanza de 14 personas en los eventos conocidos como "Barrios Altos", acaecida en noviembre de 1991. El general Robles reveló los nombres de los militares que integraban este "escuadrón de la muerte" e indicó que el Comandante General del Ejército, general Nicolás de Bari Hermoza Ríos y el asesor del presidente Fujimori, el seńor Vladimiro Montesinos, se encontraban involucrados como encubridores y autores intelectuales de estos hechos (Comision Interamericana De Derechos Humanos, 1999).

Como consecuencia de la demanda emitida, el general Robles se vio en vuelto en problemas con la justicia militar, la cual fue llevado a presión y; "Pasar a Situación de Retiro, con fecha 10 de mayo de 1993, al general de División Rodolfo Robles Espinoza, por Medida Disciplinaria, al haber cometido graves infracciones disciplinarias contra el Servicio, el Honor, Decoro y Deberes Militares" (Cidh.org, 1999).

Debido a la diferente acusación en su contra, por ultraje a la nación y a las Fuerzas Armadas, es también importante recalcar que la denuncia pública realizada en contra del señor Vladimiro Montesinos Torres jefe del Sistema de Inteligencia, y el general Nicolás Hermosa Ríos Comandante de las Fuerzas Militares; El general Robles fue víctima de amenazas en contra de su vida e integridad personal, una de las situaciones más conmovedoras que le sucedió fue que, "Después de la denuncia del general Robles, la cúpula castrense dio la orden de desaforar del Hospital Militar a su señora madre, doña Estefanía Espinoza, de 83 años. La abandonaron en los pasillos por dos horas. Sufría de hipertensión y cardiopatía hipertensiva" (LA REPUBLICA, 2011).

De acuerdo a los hostigamientos y malos tratos que recibía por parte del Estado, su familia salió gravemente perjudicada por la falta de seguridad que tenían en Perú, 
producto de ello, el general Rodolfo Robles Espinoza se vio obligado a salir del país y pedir el apoyo a la embajada de los Estados Unidos; "El día 7 de mayo de 1993, por gestiones realizadas por la Embajada de los Estados Unidos, el general Rodolfo Robles Espinoza pudo trasladarse a la República de Argentina, en calidad de exiliado. Junto con el general Espinoza se vieron obligados a abandonar el país sus hijos, José y Rodolfo Robles Montoya, ambos oficiales militares del Ejército peruano" (cidh.org, 1999).

Otro de los atentados en donde los militares se han visto involucrados injustamente es en la operación Chavín de Huántar, una operación exitosa a nivel mundial debido a los resultados obtenidos, pero por otro lado es una de las operaciones donde muchos militares se han visto involucrados en problemas con la justicia militar; Condenados debido a la demanda interpuesta contra el Estado peruano por el caso de la muerte del terrorista Eduardo Cruz Sánchez 'tito'.

El coronel en retiro Roberto Huamán Azcurra quien tenía a su cargo el servicio de inteligencia del Ejército, pese a la sentencia que le impusieron, su familia fue víctima de aquellos cargos que lo inculpaban; "debido a que el segundo Juzgado Penal Liquidador embargó las propiedades del coronel en retiro, Roberto Huamán Azcurra por S/.250 mil, como concepto de la reparación civil que debe al Estado peruano" (PERU21, 2013).

\section{Conclusiones}

\section{Desde la perspectiva familiar y social}

La libertad sin duda, es un derecho con el que nacemos cada uno de los seres humanos, indiscutiblemente un privilegio del que todos queremos disfrutar. Los Militares están siempre expuestos a la privación de su libertad, pues el cumplimiento de su deber los lleva muchas veces a cometer errores fatales que traen consigo un sin número de consecuencia, familiares, profesionales y sociales.

Pues bien, siendo la familia la base de la sociedad, es también la base y el equilibrio emocional de toda persona, por ello, se pudo evidenciar aquí que uno de los efectos más desequilibrantes en los militares condenados, ha sido la inestabilidad de la familiar, ha quedado demostrado que muchas familias se han desintegrado por diferentes motivos, no ha sido fácil conservar la unidad pues es de tener en cuenta que la cabeza del hogar es el hombre y estando éste ausente, todo se ha complicado.

\section{Desde la perspectiva laboral y legal}

Los conflictos armados atravesados por los diferentes países evidentemente han dejado consecuencias, abusos y efectos colaterales, De acuerdo con el General 
Fernando Tapias en una entrevista concedida a la periodista María Jimena Duzán ejemplifica entre los efectos colaterales de "cuando usted está en un combate y pierde la noción del empleo de la fuerza porque la situación se desarrolla en una forma tan compleja que no se pueden controlar" (Revista Semana, 2013).

Se plantea la incógnita de si verdaderamente es justo que quienes cometieron actos terroristas como los que se tomaron el Palacio de Justicia o la Embajada Japonesa en Perú estén gozando de todas las garantías democráticas mientras que los militares que, por orden del mismo gobierno, del presidente y sus ministros, intervinieron, estén en la cárcel.

Las sugerencias de expertos frente a estas situaciones consideran pertinente la creación de un Código de Justicia Penal Militar que tenga en cuenta todos los aspectos que implican un operativo militar, y a la vez se brinden alternativas para los casos especiales de militares condenados.

\section{Bibliografía}

Aguilas Humanas. (07 de Junio de 2010). Águilas Humanas. Obtenido de Águilas Humanas: http:// aguilashumanas.blogspot.com.co/2010/06/carcel-de-marcos-paz-una-cronica-desde.html

Asociación Americana de Juristas. (1997). desaparecidos.org. Obtenido de desaparecidos.org: http:// www.desaparecidos.org/arg/doc/secretos/info.html

Asociación de Abogados por la Justicia y la Concordia. (25 de Agosto de 2015). Unión de promociones. Obtenido de Unión de promociones: http://uniondepromociones.info/articulos/Como-semata-a-los-PP-en-Argentina-hoy-8va-actualizacion-25-Ago-15.pdf

Castro, C. S. (s.f.). Reforma del derecho penal militar. Recuperado el 30 de junio de 2016, de https:// www.unifr.ch/ddp1/derechopenal/anuario/an_2001_07.pdf

Centro de Información Judicial. (10 de abril de 2012). Centro de Información Judicial. Obtenido de Centro de Información Judicial: http://www.cij.gov.ar/nota-8914-Procesaron-a-nueve-acusados-en-causa-por-delitos-de-lesa-humanidad-en-Bah-a-Blanca.html

Clarín. (01 de Junio de 2014). Clarín. Obtenido de Clarín: http://www.clarin.com/politica/TrasladaronEzeiza-represores_0_1149485074.html

Congreso.gob. (s.f.). Obtenido de ley de organización y funciones de fuero militar policial.:

http://www2.congreso.gob.pe/Sicr/RelatAgenda/proapro.nsf/ProyectosAprobadosPortal-D6CB 1A5FCU74F052573B600032A12/\$FILE/1421FUEROMILITAR.pdf

Correa, J. A. (s.f.). Centro Colombiano de Pensamiento Politico-Militar. Obtenido de Centro Colombiano de Pensamiento Político-Militar: http://pensamientopolitico-militar.blogspot. com.co/2012/04/la-injusta-justicia-colombiana-sigue.html

corteidh.or. (29 de noviembre de 2006). Recuperado el 30 de junio de 2016, de Corte Interamericana de derechos humanos: http://www.corteidh.or.cr/docs/casos/articulos/seriec_162_esp.pdf 
EL ESPECTADOR. (13 de enero de 2016). El Espectador. Obtenido de El Espectador: http://www. elespectador.com/noticias/judicial/coronel-r-sanchez-rubiano-califico-fallo-condenatorio-i-articulo-610235

EL MUNDO.es. (03 de septiembre de 2010). EL MUNDO.es. Obtenido de http://www.elmundo.es/ america/2010/09/03/argentina/1283529113.html

EL TIEMPO. (12 de enero de 2016). El Tiempo. Obtenido de El Tiempo: http://www.eltiempo. $\mathrm{com} /$ politica/justicia/condenan-al-coronel-edilberto-sanchez-rubiano-por-el-palacio-de-justicia/ 16478953

EQUIPO NIZKOR. (s.f.). derechos.org. Obtenido de derechos.org: http://www.derechos.org/ddhh/ arg/ley/conadep.txt

Gabetta, C. (12 de marzo de 2016). perfil.com. Obtenido de perfil.com: http://www.perfil.com/ columnistas/Un-capitulo-que-es-necesario-cerrar-20160311-0076.html

LA NACIÓN. (23 de noviembre de 2015). LA NACIÓN. Obtenido de LA NACIÓN: http://www. lanacion.com.ar/1847930-no-mas-venganza24

La silla vacía. (16 de junio de 2011). La silla vacía. Obtenido de La silla vacía: http://lasillavacia. com/historia/lo-que-el-procurador-olvido-mencionar-del-testigo-suplantado-del-caso-plazas-vega- 25196

LaRepublica.pe. (17 de mayo de 2005). Recuperado el 30 de junio de 2016, de http://larepublica.pe/1705-2005/nicolas-hermoza-rios-fue-condenado-ocho-anos-de-prision-por-robarle-al-ejercito

Loaiza, R. N. (05 de febrero de 2012). Centro Colombiano de Pensamiento Político-Militar. Obtenido de Centro Colombiano de Pensamiento Político-Militar: http://pensamientopolitico-militar. blogspot.com.co/2012/04/la-injusta-justicia-colombiana-sigue.html

Pérez, C. O. (9 de junio de 2016). (C. P. Estefany, Entrevistador)

PERU21. (10 de MAYO de 2013). PERU21. (viernes 10 de mayo del 2013) Recuperado el 16 de ABRIL de 2016, de http://peru21.pe/politica/embargan-bienes-huaman-azcurra-2130416

Prensa de la Comisión Juicio Campo de Mayo. (04 de Julio de 2012). Comisión Juicio Campo de Mayo. Obtenido de Comisión Juicio Campo de Mayo: https://comisionjuiciocampodemayo.wordpress.com/videos/listado-de-condenados-por-delitos-de-lesa-humanidad/

Red de información jurídica. (s.f.). Recuperado el 30 de junio de 2016, de http:// www2.congreso.gob.pe/sicr/cendocbib/con2_uibd.nsf/EA9A8080B8286E120 5257799007ACCB6/\$FILE/Just_Militar_Situacion_Actual.pdf

Renteria, J. A. (s.f.). Corte constitucional. Obtenido de corte constitucional: http://www. corteconstitucional.gov.co/relatoria/2001/C-676-01.htm

Revista Semana. (13 de abril de 2013). Centro Colombiano de Pensamiento Político-Militar. Obtenido de Centro Colombiano de Pensamiento Político-Militar: http://pensamientopolitico-militar.blogspot.com.co/2012/04/la-injusta-justicia-colombiana-sigue. html.

Estefany Pita Tunjar, 2017, Tesis de pregrado, Escuela Militar de Cadetes "General José María Córdova”, Bogotá. 
Santi, M. D., \& Riera, A. (09 de Julio de 2015). Chequeado. Obtenido de chequeado: http:// chequeado.com/ultimas-noticias/zannini-un-hito-son-los-521-acusados-de-crimenesde-lesa-humanidad-ya-condenados-o-los-1200-en-proceso/

Vedia, M. d. (04 de junio de 2014). LA NACIÓN. Obtenido de LA NACIÓN: http://www. lanacion.com.ar/1698137-polemico-traslado-de-88-represores-a-la-carcel-de-ezeiza

Ybarra, G. (07 de agosto de 2008). LA NACIÓN. Obtenido de LA NACIÓN: http://www. lanacion.com.ar/1037285-derogaron-el-codigo-de-justicia-militar 